\title{
Congenital nystagmus and negative electroretinography
}

This article was published in the following Dove Press journal:

Clinical Ophthalmology

5 April 201I

Number of times this article has been viewed

\section{Mirella Roussi \\ Hélène Dalens \\ Jean Jacques Marcellier \\ Franck Bacin}

Department of Ophthalmology, Clermont-Ferrand University, Clermont-Ferrand, France
Correspondence: M Roussi Department of Ophthalmology, Clermont-Ferrand University, Clermont-Ferrand, France

Tel +3304 $7375 \quad$ I468

Fax +33047375 I450

Email bomous8I@yahoo.fr
Abstract: Congenital nystagmus is a pathologic oculomotor state appearing at about three to four months of age. The precise diagnosis requires detailed clinical examination and electrophysiological findings. This case report presents two male patients with congenital nystagmus examined longitudinally from the age of six months until 17-18 years of age. Clinical and electrophysiological protocols were detailed. The first results showed electronegative electroretinography in the two cases and examination combined with electroretinographic findings helped us to make the diagnosis of Congenital Night Stationary Blindness (CSNB). This diagnosis was confirmed by genetic studies. CSNB is interesting to study because through electrophysiological findings, it enables a better understanding of the physiology of neural transmission in the outer part of the retina.

Keywords: Congenital nystagmus, negative electroretinography, congenital night stationary blindness

\section{Introduction}

Congenital nystagmus is a pathologic oculomotor state observed before the maturation of visual function, and appearing at about 3-4 months of age. Morphologically, the form may be pure jerk, pure pendular, or both jerk and pendular in different gaze directions. As described by Gottlob, ${ }^{1}$ nystagmus is a nonspecific manifestation of a wide variety of disorders of the eye, visual pathways, or central nervous system. After cycloplegic refraction, the ophthalmologist will search for a sensory defect, such as cataract, corneal opacities, aniridia, chorioretinal coloboma, and albinism, which are the most frequent causes of such visual abnormalities. Moreover, neurological impairment must be eliminated. With other causes, such as Leber's amaurosis, achromatopsia, or congenital night stationary blindness (CSNB), the eyes are grossly normal. Clinical analysis of the nystagmus may give clues to the diagnosis. The pendular type of nystagmus is associated with ocular albinism, retinoschisis, achromatopsia, and CSNB. ${ }^{2}$ These congenital disorders require differentiation by detailed clinical examination, and by electrophysiological findings under photopic and scotopic conditions.

\section{Case reports}

Two male patients aged 18 years (Case 1) and 17 years (Case 2) were examined longitudinally. The first examination was performed at six months of age, the next at 10 and 11 years of age, and the last at 17 and 18 years of age.

At six months, we performed refractive measurement, slit lamp examination, funduscopy, and electroretinogram (ERG) studies using the Biophysic Medical Pantops PC2 (v 2.53 FRA 1991; Biophysic Medical, Clermont-Ferrand, France). We used contact lens electrodes (Dencott, Paris, France) for recording. After dark-adaptation for 
10 minutes, we recorded a scotopic blue ERG. The patients were then light-adapted for three minutes at $100 \mathrm{~cd} / \mathrm{m}^{2}$ and a photopic white and red ERG was recorded.

At 10 and 11 years of age, we performed refractive measurements, funduscopic examination, a Roth 28-Hue color vision test, a Goldman visual field test, and ERG with a Monitor Win5000H (Metrovision, Paris, France). We recorded a photopic red, white, and flicker ERG and a scotopic blue ERG.

At 17 and 18 years of age, we performed refractive measurement, fundi examination, Roth 28-Hue color vision test, Goldman visual field examination, and optical coherence tomography of the macula. To perform ERG studies, we used the Metrovision vision monitor. The ERG and the electrooculogram (EOG) were recorded as described by the most recent International Society for Clinical Electrophysiology of Vision standard. ${ }^{3}$

Full-field (Ganzfeld) stimulation was used. Recording electrodes comprised corneal contact lens electrodes. The corneal surface was protected by a nonirritating ionic conductive solution (methylcellulose $0.5 \%$ ). Topical anesthesia was used. The impedance of the applied electrode measured about $3 \mathrm{kOhms.}$ Reference electrodes were placed near each orbital rim as a reference for the corresponding eye. Ground electrodes were placed on the forehead. The skin was prepared by cleaning, and a conductive paste was used to ensure a good electrical connection. Pupils were maximally dilated with tropicamide $1 \%$.

\section{Electrophysiology protocol}

To record a dark trough for the EOG, the room light was turned off and EOG values were recorded for 15 minutes in darkness. The minimum amplitude during this period was designated as the dark trough. The light stimulus was turned on and the EOG was recorded, until the light peak occurred and the signal amplitudes had clearly started to descend, at which point the recording was stopped. When the pupils were dilated, the stimulus intensity was $80 \mathrm{~cd} / \mathrm{m}^{2}$.

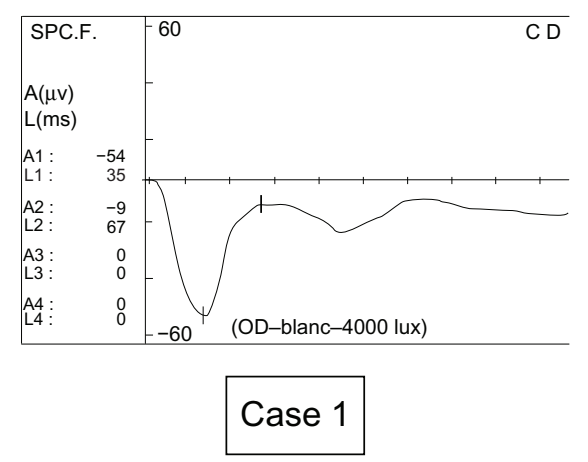

Figure I Negative electroretinogram at six months (199I and 1992). Case I. White photopic electroretinogram of the right eye. Case 2. White photopic electroretinogram of the left eye.

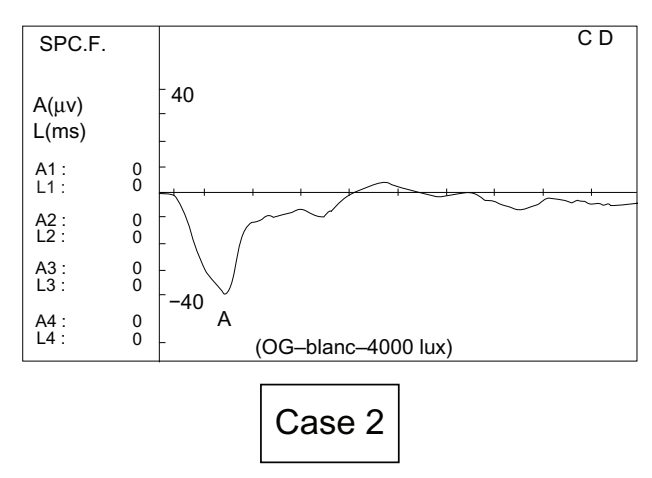

For rod ERG recording, the patients were dark-adapted for at least 20 minutes beforehand. The stimulus was a dim white flash $\left(0.01 \mathrm{~cd} / \mathrm{s} / \mathrm{m}^{2}\right)$. The interval between two flashes was 1944 msec (approximately two seconds). We recorded eight accumulations for each patient.

The mixed ERG was produced by a white single flash stimulus $\left(3 \mathrm{~cd} / \mathrm{s} / \mathrm{m}^{2}\right)$ to the dark-adapted eye. The interval between stimuli was $7222 \mathrm{msec}$ (approximately seven seconds). We recorded eight accumulations for each patient.

Dark-adapted oscillatory potentials were generally obtained from the dark-adapted eye using the same white single flash $\left(3.0 \mathrm{~cd} / \mathrm{s} / \mathrm{m}^{2}\right)$ and a high-pass filter $(100 \mathrm{~Hz})$.

For cone (light-adapted) ERG recordings, the patients were light-adapted for 10 minutes. The stimulus was a white single flash $\left(500 \mathrm{~cd} / \mathrm{s} / \mathrm{m}^{2}\right)$, and the rods were suppressed by a background with a luminance of $30 \mathrm{~cd} / \mathrm{s} / \mathrm{m}^{2}$. The interval between stimuli was $500 \mathrm{msec}$. We recorded 30 accumulations for each patient. A $30 \mathrm{~Hz}$ light-adapted flicker ERG was also used to represent the cone system. A white stimulus $(500 \mathrm{~cd} /$ $\mathrm{m}^{2}$ ) was used, with approximately 30 stimuli per second.

\section{Results \\ Examination and recordings at six months of age}

In both cases, nystagmus had been noticed by the mothers at 3-4 months of age. In Case 1, at examination, the nystagmus was a vertical pendular type. In Case 2, the nystagmus was pendular with a horizontal and vertical gaze. Funduscopy and slit lamp examination was normal in both cases. The first ERG at six months, performed under general anesthesia, showed a negative type in our two young patients (Figure 1).

\section{Examination and recordings}

\section{at I0-II years}

In Case 1, visual acuity was 0.16 , with a hyperopic error of +1 . The nystagmus was amplified on monocular vision. 
We observed an esotropia of 12 prism diopters (PD) in the left eye. The fundi stayed normal. In Case 2, visual acuity was 0.1 with a myopic error of -4 . Nystagmus was idem on monocular or binocular vision. We did not observe any strabismus. The fundi stayed normal. 28-Hue color vision and Goldmann visual field tests were normal in both cases. The ERG showed a negative profile (Figure 2).

\section{Examination and recordings at $17-18$ years}

At the age of 17, Case 1 had a corrected visual acuity of 0.32 with a mild hyperopic refractive error $(+1)$ and showed an esotropia of 16 PD. At the age of 18 years, Case 2 had a corrected visual acuity of 0.2 with a mild myopic refractive error (-4). The fundi remained normal in both cases. Optical coherence tomography of the macula showed no sign of $\mathrm{x}$-linked retinoschisis in either case. Goldman visual field and 28-Hue color vision tests were normal in both cases. This completed our electrophysiological examination.

Figure 3 reflects the activity of the retinal pigment epithelium and photoreceptors. In Case 1, it was subnormal in the right eye but affected in the left eye, probably because of the esotropia. In Case 2, it was normal in both eyes. Therefore, the visual pigments and photoreceptors were normal, indicating that the basic abnormality could be in neural transmission at a some level in the outer part of the retina.

Rod response (dark-adapted) ERG was recordable but lowered (see Figure 4). This reflected activity of bipolar cells in the rods. In the complete form of CSNB, the rod response is nonrecordable but is recordable in the incomplete form, albeit lower than in normal subjects. ${ }^{5}$

Mixed response (dark-adapted) ERGs showed a negative profile (see Figure 5), reflecting impairment of the ON pathway of both rods and cones. ${ }^{4}$ There was no difference between the complete and incomplete form of CSNB. ${ }^{5}$

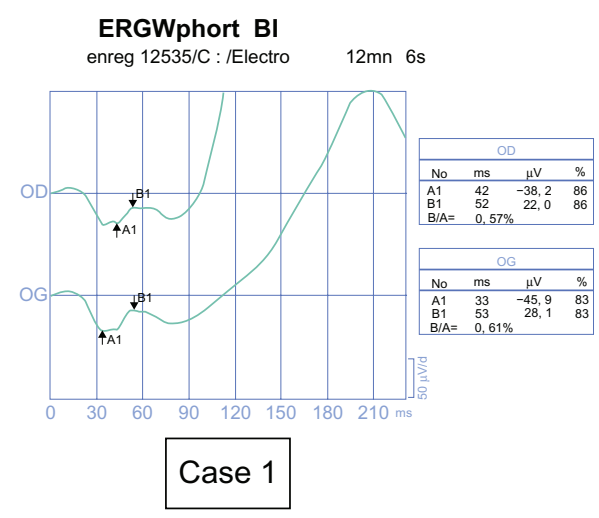

The cone response (light-adapted ERG) also showed a negative profile (see Figure 6) and reflects the impairment of the ON and OFF pathway of the cones. ${ }^{6}$ Moreover, Miyake et $\mathrm{al}^{5}$ showed that analysis of differences in the b-wave amplitude is very interesting. Indeed, the mean and two standard deviations of the b-wave were $73 \pm 25 \mu \mathrm{V}$ in normal subjects, $52 \pm 34 \mu \mathrm{V}$ in patients with complete CSNB, and $18 \pm 26 \mu \mathrm{V}$ in patients with incomplete CSNB.

The amplitude of the light-adapted flicker response (peak to trough) was smaller and reflected impairment of the cone response by ON or OFF bipolar cells (Figure 7). ${ }^{3}$ The mean amplitude and two standard deviations were $43 \pm 20 \mu \mathrm{V}$ in normal subjects, $33 \pm 18 \mu \mathrm{V}$ in patients with complete CSNB, and $11 \pm 8 \mu \mathrm{V}$ in patients with incomplete CSNB. ${ }^{2}$

Dark-adapted oscillatory potentials (Figure 8) were lowered, and the smallest was phot-OP 4. Impairment of phot-OP 4 is specific for incomplete CSNB and reflects specific impairment of the cone OFF pathway. In the complete form, phot-OP 2 and 3 are lowered, but phot-OP 4 is normal. ${ }^{5}$

\section{Discussion}

The basic underlying retinal pathology for all electronegative ERGs is a disturbance at or proximal to the inner segments of the photoreceptors, but relative sparing of photoreceptors and function of the outer segments. The age of onset, type of nystagmus, and the first negative ERG profile led us to the suspicion of an inherited retinal disorder in our patients, in whom we found stationary inherited retinal disease with negative ERG and normal fundi, normal macular optical coherence tomography, normal color vision, and normal visual fields. As a result of the electrophysiological findings, our main hypothesis was CNSB in its incomplete form, because in the complete form of CSNB rod ERG is not recordable, but is recordable and with smaller cone ERG amplitude in the incomplete form. The flicker response is

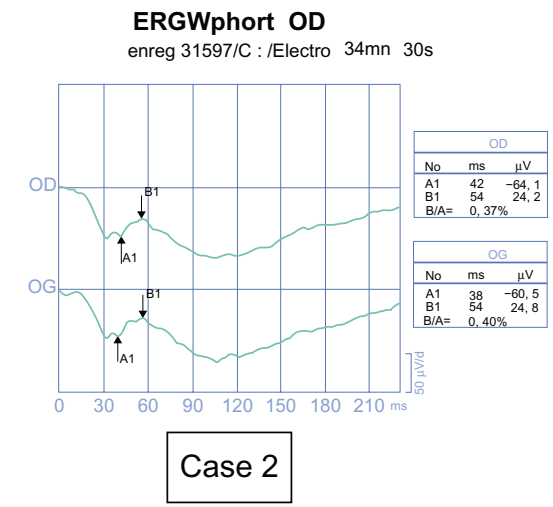

Figure 2 Electroretinograms stayed negative when they were controlled in 2002 (Case I, II years; Case 2, 10 years). Case I. Negative profile of the photopic electroretinogram with white flash (b-wave amplitude) $37.8 \mathrm{~V}$ in the right eye and $43.1 \mathrm{~V}$ in the right eye). Case 2. Negative profile of the photopic electroretinogram with white flash (b-wave amplitude $24.2 \mathrm{~V}$ in the right eye and $24.8 \mathrm{~V}$ in the left eye). 

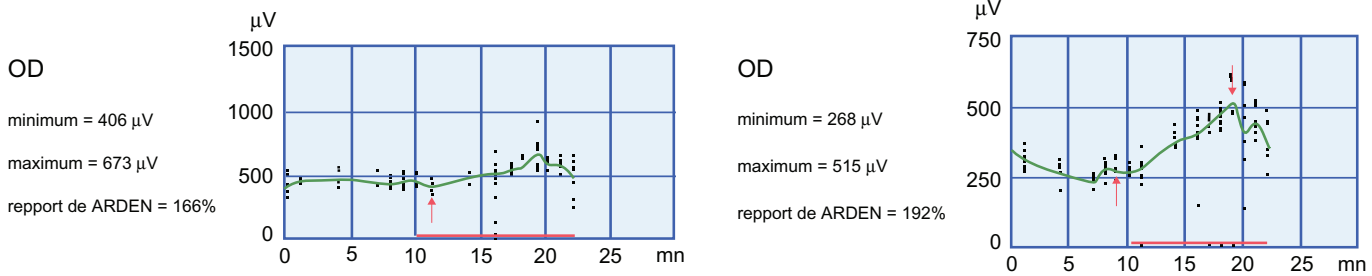

OG

minimum $=428 \mu \mathrm{V}$

maximum $=456 \mu \mathrm{V}$

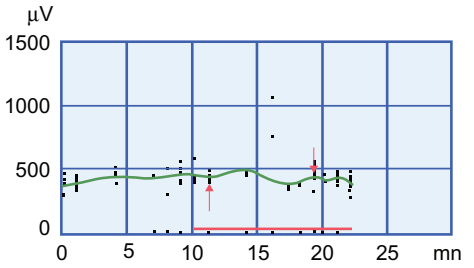

OG

minimum $=247 \mu \mathrm{V}$

maximum $=522 \mu \mathrm{V}$

repport de ARDEN $=107 \%$

epport de ARDEN $=212 \%$

\section{Case 1}

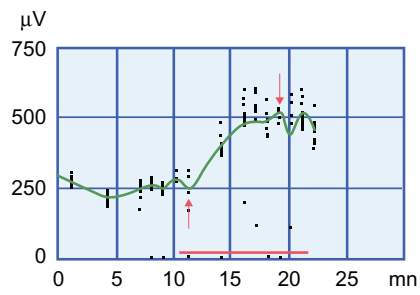

Case 2

Figure 3 Red arrows indicate the dark trough (first arrow) and the light peak (second arrow) and the red line along the $\mathrm{x}$ axis indicates the duration that the background light is on. Case I. Altered electro-oculogram in the left eye because of esotropia, and subnormal electro-oculogram with Arden ratio $66 \%$ on the right eye, probably due to the nystagmus being raised on monocular vision. Case 2. Both eyes are normal (Arden ratio 192\% and 212\%). The normal value of the Arden ratio is over $185 \%$.

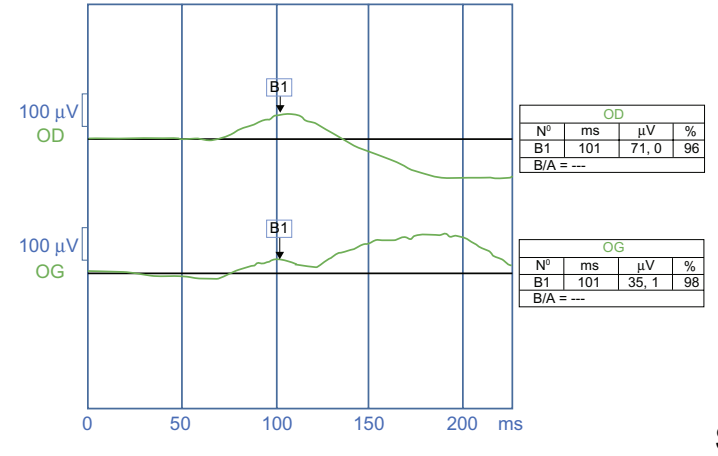

Case 1

Figure 4 Lowered rod response recordable.

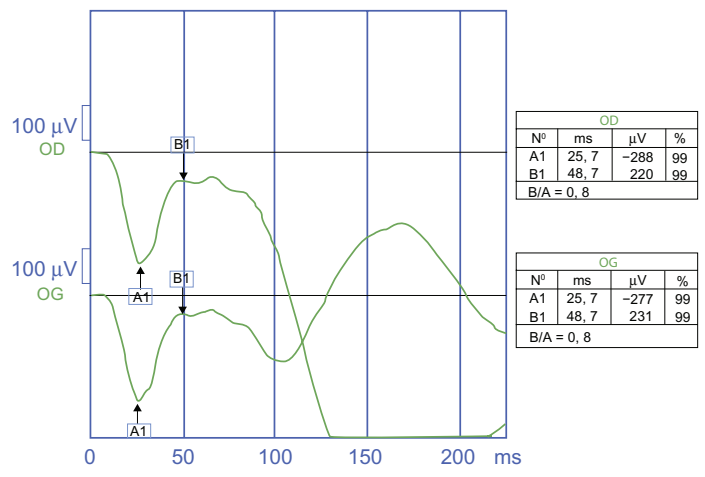

Case 1

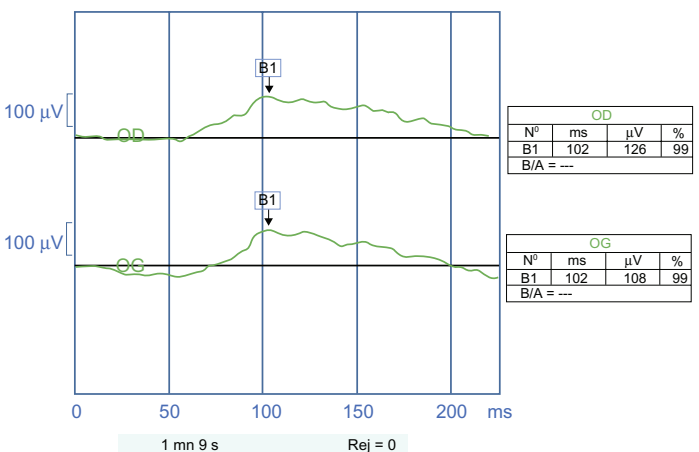

Case 2

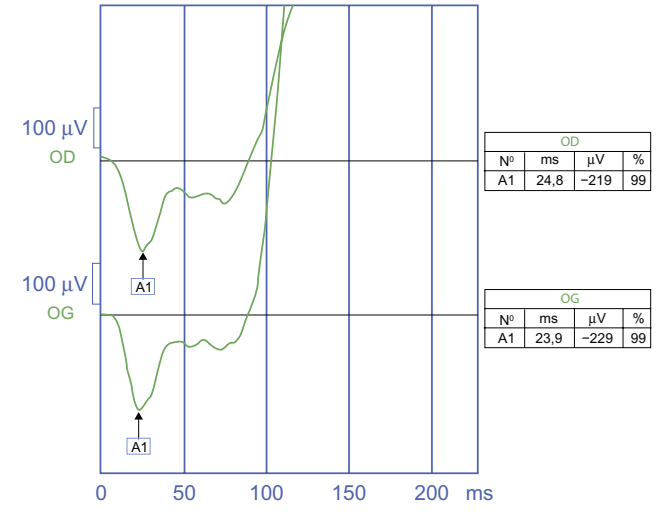

Case 2

Figure 5 Negative profile of the mixed response. 

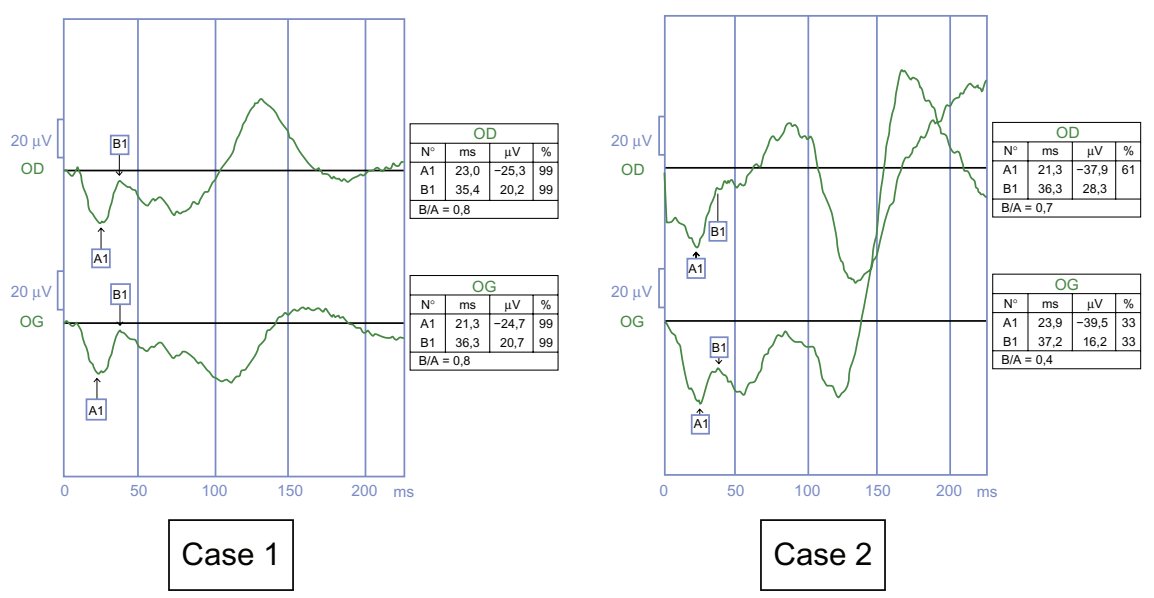

Figure 6 Case I. Negative profile and b-wave amplitude is $20.2 \mu \mathrm{V}$ on the right eye, $20.7 \mu \mathrm{V}$ in the left eye, in the range of those of incomplete congenital night stationary blindness. Case 2. Negative profile and b wave amplitude is $16.2 \mu \mathrm{V}$ and on the left eye, and $32.1 \mu \mathrm{V}$ on the right eye but in the range of complete congenital night stationary blindness.

smaller in the incomplete form than in the complete form. Furthermore, in the oscillatory potential, phot-OP 4 is not recordable in the incomplete form whereas it is normal in the complete form.

CSNB was first described in 1952 by Schubert-Bornschein. Clinically, it is an association between an x-linked recessive hereditary mode, a lowered visual acuity, a nystagmus with normal fundi, and a negative ERG. However, there are some differences between patients with CSNB, and a subtype was apparent. Miyake, in 1986, defined this subtype as the incomplete form of CSNB on the basis of electrophysiological findings. ${ }^{7}$

Pathophysiological studies suggest that patients with complete CSNB have an almost complete block of synaptic transmission from photoreceptors to the $\mathrm{ON}$ bipolar cells in both rod and cone visual pathways, whereas the OFF pathway appears to be intact. In contrast, patients with incomplete

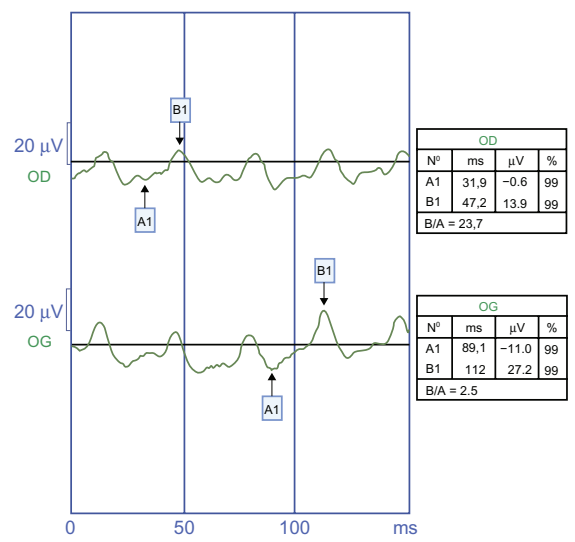

Case 1
CSNB have an incomplete defect of the synapses on the ON and OFF bipolar cells in the rod and cone visual pathways.

Evidence of genetic heterogeneity in x-linked complete and incomplete CSNB was reported by Boycott et al in 1998 . The gene for incomplete CSNB was identified by Storn et al and Bech-Hansen et al as the pore-forming subunit of a Type 2 voltage-gated calcium channel found in the retina. Loss of this functional channel impairs calcium influx into the rods and cones that is needed for sustaining tonic release of neurotransmitters from the presynaptic terminals. ${ }^{8}$ The gene for complete CSNB was identified in 2000 by Bech-Hansen as NYX, encoding the extracellular protein, nyctalopin, that guides and promotes the formation and function of the ON pathway of the retina. Therefore, in 2002, Miyake ${ }^{7}$ renamed the two types, ie, Type 1 (the complete form) and Type 2 (the incomplete form). Sieving et al analyzed the ERG abnormalities created

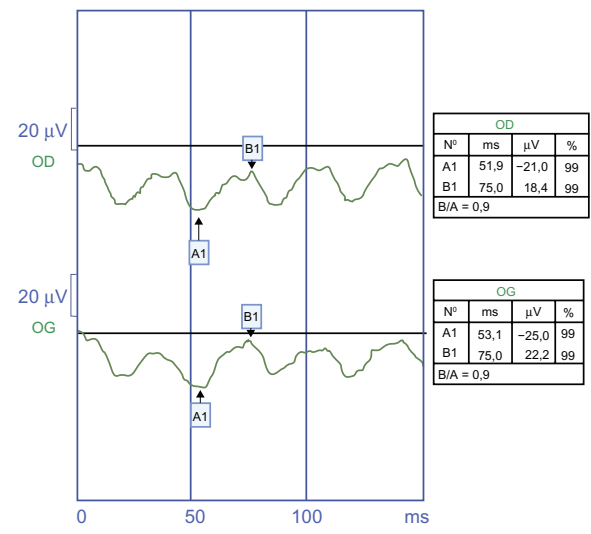

Case 2

Figure 7 Case I. Amplitude of the flicker response is $12.3 \mu \mathrm{V}$ in the right eye and 16.2 in the left eye. Case 2 . Amplitude of the flicker response is $2.6 \mu \mathrm{V}$ in the right eye and $2.8 \mu \mathrm{V}$ in the left eye. These results are compatible with incomplete congenital night stationary blindness. 

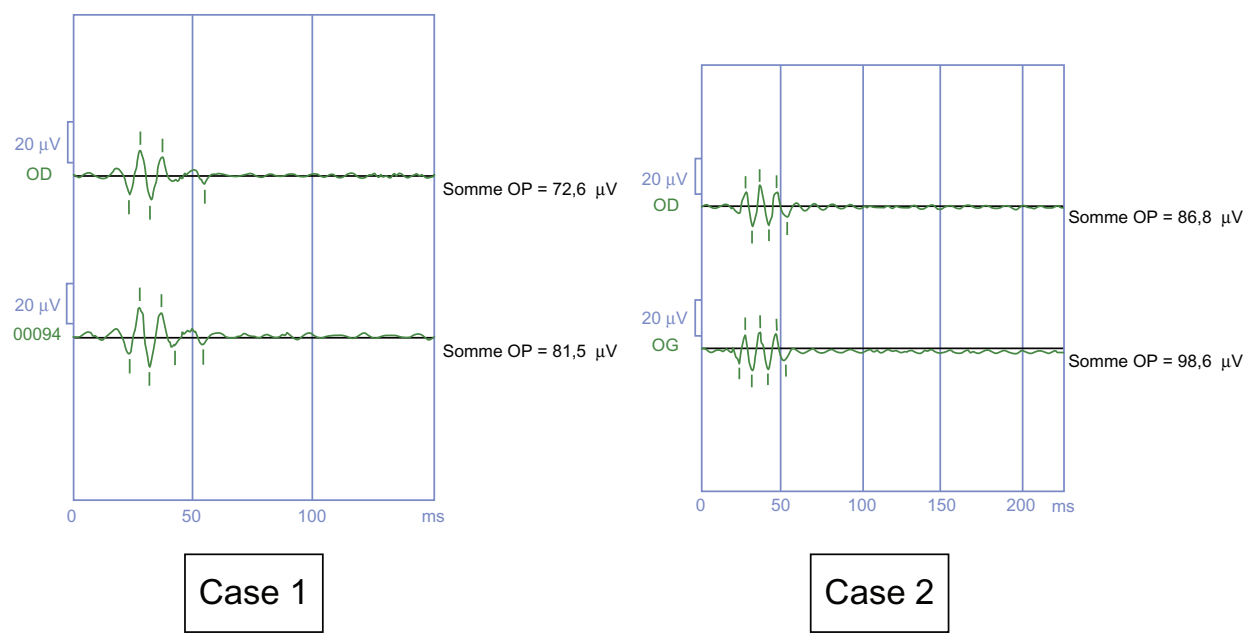

Figure 8 Reduction of oscillatory potentials, the lowest being phot-OP 4.

in anesthetized nonhuman primates by intravitreal application of glutamate analogs that selectively suppress retinal $\mathrm{ON}$ or OFF bipolar cell activity. ${ }^{9}$ 2-amino-4-phosphonobutyric acid, which selectively blocks light responses in the ON pathway and depolarizes bipolar cells, fully reproduced the essential ERG abnormalities found in human Type 1 CSNB when the OFF pathway remained active.

\section{Conclusion}

These two cases of congenital nystagmus required electrophysiological investigation to make the diagnosis, which were subsequently confirmed by genetic studies. They were shown to be two cases of Type 2 (incomplete) CSNB. It is an important diagnosis to be able to give to young patients, because CSNB is a static disease, unlike retinitis pigmentosa or cone-rod dystrophy, for example, which are degenerative disorders. CSNB is a very interesting area of research because, via electrophysiological findings, it enables a better understanding of the physiology of neural transmission in the outer retina.

\section{Disclosure}

The authors report no conflicts of interest in this work.

\section{References}

1. Gottlob I. Nystagmus. Curr Opin Ophthalm. 2000;11:330-335.

2. Pieh C, Simonsz-Toth B, Gottlob I. Nystagmus characteristics in congenital stationary night blindness (CSNB). Br J Ophthalmol. 2008;92: 236-240.

3. Marmor MF, Fulton AB, Holder GE, Miyake Y, Brigell M, Bach M. International Society for Clinical Electrophysiology of Vision. ISCEV Standard for full-field clinical electroretinography (2008 update). Doc Ophthalmol. 2009;118:69-77.

4. Rigaudière F, Le Gargasson J-F. Oeil et Physiologie de la Vision: V-Exploration électrophysiologique. Available from: http://lodel.irevues. inist.fr/oeiletphysiologiedelavision/index.php?id=115. Accessed on February 5, 2011.

5. Miyake Y, Yagasaki K, Horiguchi M, Kawase Y, Kanda T. Congenital night stationary blindness with negative electroretinogram: A new classification. Arch Ophthalmol. 1986;104:1013-1020.

6. Fulton AB, Hansen RM. Stimulus-response functions for the scotopic b-wave. In: Heckenlively JR, Arden GB, editors. Handbook of Clinical Electrophysiology of Vision. 2nd ed. Cambridge, MA: The MIT Press; 2006.

7. Miyake Y. Establishment of the concept of new clinical entities complete and incomplete form of congenital stationary night blindness. Nippon Ganka Gakkai Zasshi. 2002;106:737-755.

8. Mansergh F. Mutation of the calcium channel gene CACNA1f disrupts calcium signaling, synaptic transmission and cellular organization in mouse retina. Hum Mol Genet. 2005;14:3035-3046.

9. Khan NW, Kondo M, Hiriyanna KT, Jamison JA, Bush RA, Sieving PA. Primate retinal signaling pathways: Suppressing ON-pathway activity in monkey with glutamates analogues mimics Human CSNB1-NYX congenital night blindness. J Neurophysiol. 2005;93:481-492.
Clinical Ophthalmology

\section{Publish your work in this journal}

Clinical Ophthalmology is an international, peer-reviewed journal covering all subspecialties within ophthalmology. Key topics include: Optometry; Visual science; Pharmacology and drug therapy in eye diseases; Basic Sciences; Primary and Secondary eye care; Patient Safety and Quality of Care Improvements. This journal is indexed on

\section{Dovepress}

PubMed Central and CAS, and is the official journal of The Society of Clinical Ophthalmology (SCO). The manuscript management system is completely online and includes a very quick and fair peer-review system, which is all easy to use. Visit http://www.dovepress.com/ testimonials.php to read real quotes from published authors. 